\title{
The Acceptance and Use of Online Shopping by the Digital Natives and Digital Immigrants
}

\author{
Rasslene Rass Rasalingam ${ }^{1}$, Balakrishnan Muniandy ${ }^{2}$, Rasslenda-Rass \\ Rasalingam ${ }^{3}$ \\ ${ }^{123}$ (Centre for Instructional Technology and Multimedia, Universiti Sains Malaysia, Malaysia)
}

\begin{abstract}
This article discusses the acceptance and use of online shopping by the digital natives and digital immigrants. Online shopping means the act of purchasing products or services over the Internet. Today, online shopping using the Internet is gaining attention. Online shopping has been growing in tandem with the growth of the Internet. More and more people are leaning towards online shopping. Despite this growth, we are not sure how the digital immigrants are using the development of the Internet for online shopping. We also do not know if there is any difference in the pattern of online shopping use between the savvy digital natives and digital immigrants. The focus of this research is to study the acceptance and use of online shopping by the digital natives and digital immigrants. This is to compare the pattern between both the generations and also to find out how effective is this online shopping. This study was carried out by using survey questionnaire. The instrument for this study was developed and modified from Davis's Technology Acceptance Model (TAM). A total of 200 respondents from both the generations participated in this study. The research instrument was validated by two experts in the related field. As for the reliability of the instrument, the Cronbach alpha value obtained was 0.959. This research finding showed the characteristics and differences in the pattern of online shopping between the two generation in terms of usage pattern, satisfaction, perceived usefulness and ease of use. Suggestion for further research was also provided.
\end{abstract}

Keywords : Online Shopping, Digital Natives, Digital Immigrants.

\section{Introduction}

The Internet has grown dramatically year after year since the beginning of the 1990s. The diffusion of online buying transactions has been readily accepted by consumers in some countries. In other countries, the growth is slower. They seem to be less accepting towards the idea of online shopping. Until today, we can see the limitation of using the online shopping mode. Generally, online shopping has been growing in tandem with the growth of the internet. More and more people are moving towards online shopping. However, we are not sure how the digital immigrants are using the development of the Internet for online shopping. Besides that, we also do not know if there is any difference in the pattern of online shopping use between the savvy digital natives and digital immigrants. The preceding statement statements form the problem statement for the study. The objective of this research is to study the acceptance of online shopping in between the digital natives and digital immigrants. This is to compare both generations and above all to find out how effective is this online shopping.

The research finding will show why there is a difference between the digital native and the digital immigrant in terms of four main aspects; the usage pattern of online shopping, the satisfaction of online shopping, perceived usefulness, and ease of use of online shopping based on the theoretical framework of Technology Acceptance Model (TAM). Technology Acceptance Model (TAM) by Davis et al. (1989) has been applied in this study. Several factors such as usefulness and ease of use are hypothesized as predictors of online shopping by both generations were analyzed. The model was analyzed based on a sample size of 200 staffs and students of a university. Since there was no previous research investigating the factors of acceptance of online shopping among both generations, this study will gave new insights in the pattern of online shopping between the digital natives and digital immigrants. This initiative may pave a path for more research to be conducted in this area.

\subsection{Online Shopping}

\section{Literature Review}

The Internet is going to become more popular as time goes on among shoppers worldwide become more comfortable with the improved security features and on-time delivery of their purchases. According to the Business Dictionary, online shopping is the act of purchasing products or services over the Internet. Online shopping has grown in popularity over the years, mainly because people find it convenient and easy to shop from the comfort of their home or office. One of the most enticing factors about online shopping, particularly 
during a holiday season, is it alleviates the need to wait in long lines or search from a store to store for a particular item.

In the US Online Retail Forecast, 2009 to 2014 dated, November 24, 2010, by Sucharita Mulpuru, Peter Hult with Patti Freeman Evans, Vikram Sehgal, Brendan McGowan shows that \$248.7 billion online sales are expected by 2014. A compounded growth of $10 \%$ is forecasted for the next five years. In Western Europe, sales are expected to reach 14 billion Euros ( $\$ 155.7$ billion), a growth of $11 \%$ per cent annually. Apparel, computers and consumer electronics will continue to be dominant purchases; these three areas make up $40 \%$ of the current online sales which won't change in the near future. Considering that the country is in a major recession, the increase in online buying is a good sign. A survey of U.S. online customers found that $82 \%$ are satisfied with buying experiences that began and ended with the online store. Satisfaction dropped to $61 \%$ when they researched online and then bought in a store. Online sales continue to be mostly small-ticket items. The high-ticket products lag far behind by comparison. On average, retailers who have both a physical (store), and online presence have reported an average of $23 \%$ growth. Online only retailers (including catalogue sales) however, have seen only $9 \%$ yearly growth. Online shoppers are beginning to think that the best deals are available online $(71 \%)$ and that they get better prices there $(66 \%)$.

The Star Malaysia dated July 26, 2012 reported that online shopping in Malaysia continues to see incredible growth amid the global economic uncertainty in the past year. A global report released by JPMorgan in 2011 indicates that e-commerce revenue around the world is expected to hit US\$963bil this year. Closer to home, the online shopping market in Malaysia alone is expected to grow at an accelerated pace from RM842mil in 2011 to exceed RM1.9bil in 2016, according to a Euromonitor survey conducted in 2011. The buoyancy of this sector is consistently fuelled by the increasing Internet adoption, as well as a flurry of technical innovations that have changed the buyer-seller relationship irrevocably. Over the next 12 months, there are five key trends that we expect to emerge, shaping the future of online shopping across the world. The extent to which businesses in Malaysia embrace these trends will clearly shape their ability to maximize the growing ecommerce industry.

\subsection{The Digital Natives and the Digital Immigrants}

According to Wikipedia Encyclopedia, a digital native is a person who was born during or after the general introduction of digital technologies and that is those interacting with digital technology from an early age, has a greater understanding of its concepts. Alternatively, this term can describe people born during or after 1960s, as the digital age began at that time; but in most cases, the term focuses on people who grew up with the technology that became prevalent in the latter part of the 20th century and continues to evolve today and a digital immigrant is an individual who was born before the existence of digital technology and adopted it to some extent later in life. This term has also been used in several different contexts, such as education (Bennett, Maton \& Kervin 2008), higher education (Jones \& Shao 2011) and in association with the term New Millennium Learners (OECD 2008).

Zur, O. \& Zur, A. (2011), stated that "Digital Native" is a term for people born in the digital era, i.e., Generation $\mathrm{X}$ and younger. This group is also referred to as the "iGeneration" or is described as having been born with "digital DNA." In contrast, the term "Digital Immigrant" refers to those born before about 1964 and who grew up in a pre-computer world. The terms "Digital Immigrants" and "Digital Natives" were popularized and elaborated upon by Mark Prensky (2001) and critiqued for their validity and usefulness by Harding (2010) among others. In the most general terms, digital natives speak and breathe the language of computers and the culture of the web into which they were born, while digital immigrants will never deal with technology as naturally as those who grew up with it.

\subsection{Technology Acceptance Model (TAM)}

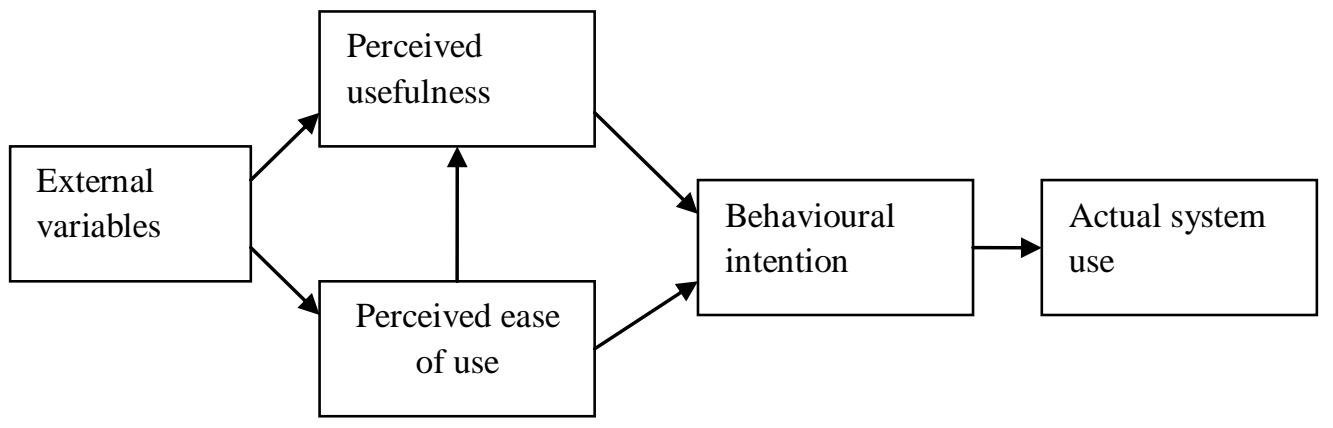

Figure 1: The Technology Acceptance Model 
In this study the researcher has used the Technology Acceptance Model (TAM) as the theoretical framework. This model is used because it is a well-known and acknowledged model, especially in information studies. Secondly, TAM is found to be an appropriate and relevant model to be included since it can be well applied to this research as a foundation for the digital immigrants and the digital native's acceptance of online shopping.

The TAM provides an explanation of the determinants of computer acceptance that is general, capable of explaining user behavior across a broad range of end-user computing technologies and user populations, while at the same time being both parsimonious and theoretically justified (Davis et al, 1989, p. 985). In 1989, Davis developed scales for two specific variables that were hypothesized to be basic determinants of user acceptance of computers. These two variables were referred to as perceived usefulness and perceived ease of use. The purpose of the study was to, through the use of these two variables to investigate why certain people tend to accept information technology and some do not (Davis, 1989).

\section{Research Question} questions:

In order to accomplish the goal of this research project, this study proposes the following research

RQ1: Is there a difference in the usage pattern of online shopping between the digital natives and the digital immigrants?

$\mathrm{RQ2}$ : Is there a difference in the degree of satisfaction between the digital natives and the digital immigrants?

RQ3: Is there a difference in perceive ease of use of online shopping between the digital natives and the digital immigrants?

RQ4: Is there a difference in perceive usefulness of online shopping between the digital natives and the digital immigrants?

RQ5: How does the digital natives and the digital immigrants perceive ease of use of online shopping?

RQ6: How do the digital natives and the digital immigrants perceive usefulness of online shopping?

\section{Research Hypothesis}

Based on the research questions, four hypotheses are derived to be tested as follows:

Ho1:

There is no significant difference in the usage pattern of online shopping between the digital natives and the digital immigrants.

Ho2:

There is no significant difference in the degree of satisfaction between the digital natives and the digital immigrants.

Ho3:

There is no significant difference in perceive ease of use of online shopping between the digital natives and the digital immigrants.

Ho4:

There is no significant difference in perceive usefulness of online shopping between the digital natives and the digital immigrants.

\subsection{Research Design}

\section{Methodology}

In this study, the researcher has chosen a descriptive survey research design which includes factfinding enquiries of different kinds. The main purpose of the descriptive research is to describe the state of affairs as it exists at present. This research study is aimed at learning about the acceptance of online shopping between the digital natives and the digital immigrants. The chosen research approach will explore the acceptance of online shopping, usage pattern, satisfaction, perceived usefulness and ease of use. This is a quantitative research where the measurement of quantity or amount is measured. A survey instrument was used 
for this quantitative study to gather data and answer the research questions and the hypothesis.

\subsection{Study Samples}

Two hundred people are involved as samples in this study. Of these 100 are digital natives and the other 100 are digital immigrants. The type of samples selected is convenience sampling. The sample consists of staffs and graduate students from a public university in peninsular Malaysia.

\subsection{Data Collection Method}

The survey instrument was chosen as the method of data collection in this study for a number of reasons. Creswell stated that a survey design provides a quantitative or a numeric description of trends, attitudes, or opinions of a population by studying a sample of the population" (Creswell, 2003). Babbie explained that surveys were particularly useful in descripting the characteristics of a large population, because they make large samples feasible and that a large number of cases are very important for both descriptive and explanatory analyses, especially whenever several variables are to be analyzed simultaneously (Babbie, 2004). As Adams (1989) explained, survey research has the advantage in explaining outcomes in terms of other effects, and participant responses are considered as statistical evidence of success or failure. Furthermore, the precise results and the practicality in collecting data make the survey instrument an appropriate research approach for this quantitative study.

\subsection{Survey Instrument}

A survey instrument is a tool for consistently implementing a scientific protocol for obtaining data from respondents. For most social and behavioral surveys, the instrument involves a questionnaire that provides a script for presenting a standard set of questions and response options. The survey instrument includes questions that address specific study objectives and was also used to collect demographic information for calculating survey weights. In some surveys, questionnaire responses are augmented by other kinds of measurements derived from instruments. The researchers have designed their own survey instrument based on Technology Acceptance Model (TAM) research studies on usefulness and ease of use. In this study, the researcher uses a paper and pencil instrument to collect the data. The survey was chosen because the researchers will administrator the survey in person to both 100 digital natives and the 100 digital immigrants' participants. English language was used by the researcher. The first page of the survey instrument is a welcome page followed by the questions which were divided into five appropriate parts as follows:

1) Demographics

2) Usage pattern of online shopping;

3) Online shopping degree of satisfaction;

4) Perceive ease of use of online shopping; and

5) Perceive usefulness of online shopping.

The total score of each respondent in terms of "Usage Pattern", "Degree of Satisfaction", Perceived Ease of Use" and "Perceived Usefulness" were computed. For checking of the construct measured by the questionnaire, the reliability of the constructs were obtained separately. This research instrument had also been validated by two experts in the related field and the score of reliability using Cronbach alpha value is 0.959 . This shows that the instrument is highly reliable. A series of questions was asked to each participant, and within each question, several statements came from all the attributes. The participants were asked to rank the descriptive statements about perceptions of online shopping " 1 " strongly disagree to " 5 " strongly agree for Part II, III, IV and V. Contents in each part of the survey are discussed in detail in the following section.

\subsubsection{Demographics}

The first part of the survey collected demographic information and other additional personal information from participants. Basic elements of classification such as gender, age categories, were included. Demographic data collected provided the basis for evaluating the sample by comparing both digital natives and the digital immigrants. This study analyses the predictor variables of online shopping including ease of use and usefulness among 100 digital natives and 100 digital immigrants with different genders selected on the basis of convenience sampling.

\subsubsection{Usage pattern of online shopping}

The usage pattern questions have been placed in Part II of the survey instruments and this part consists of four items. With the high priority of online shopping access among participants, reporting how the online shopping is used becomes critical to understand user expectations of performance. The first part includes 
questions related to the usage patterns of online purchasing. The comparison of results of the online shopping experience between digital natives and the digital immigrants need to be identified. This is because the researchers need to analyze whether the digital natives have different online shopping experience from the digital immigrants.

\subsubsection{Online shopping degree of satisfaction}

Customer satisfaction is the key factor for customer retention and acquisition in online shopping system. Customer satisfaction with respect to online shopping can be defined as the extent to which customer's perceptions of the online shopping experiences confirm their expectation. Most customers form expectation about the product vendor, service and quality of the website that they patronize before engaging in online shopping activities.

These expectations influence their decision making and intention to shop at a certain Internet store and consequently, their decision making process and purchasing behavior. If expectations are met, customers achieve a high degree of satisfaction which influences their online shopping attitudes, intentions and decisions positively. Other factors that influence online shopper's satisfaction included convenience (Heiner et al., 2004), web site design, security/ privacy, payment, and delivery (Liu et al., 2008). In this study the researcher tested on the convenience of online shopping, cost and time constrain of online shopping, whether the information provided online are reliable or not, the satisfaction of the security problems, about the product available online, online mode of payment, the satisfaction of level on the procedure of returning / exchanging of the product purchased and about the privacy issues. In the survey instrument, the degree of satisfaction questions have been placed in Part III of the survey instruments and this part consists of ten items.

\subsubsection{Perceive ease of use of online shopping}

In the fourth part of the survey, the difference between ease of use and usefulness is that ease of use is more focused on the consumer's perception of the process that leads to the final shopping outcome, whereas usefulness refers to only the outcome of the online shopping experience. It can be concluded, in a simplified manner, that ease of use is how easy the Internet is to use as a tool for shopping, and usefulness describes how effective online shopping is in helping consumers in completing their task. A series of four questions was asked of each participant, and within each question, several statements came from the seven attributes. The participants were asked to rank order these descriptive statements about perceptions of online shopping and the questions have been placed in Part IV of the survey instruments and this part consists of eleven items.

\subsubsection{Perceive usefulness of online shopping}

Besides that, Part V of the survey instruments consists of six items. The usefulness is defined as the perception of the individual that his or her performance will be improved or enhanced by using the new technology (Davis, 1989). Dellaert et al. (2004) classifies the new technology as shopping on the Internet and the individual's performance as the outcome of the online shopping experience. One of the most obvious benefits of online shopping which cannot be overlooked is convenience. One of the most enjoyable conveniences of online shopping is the ability to shop for products or services at a time which is convenient for the consumer. Online retailers accept orders twenty four hours a day while consumers who wish to shop at traditional stores have to be available to visit the store during normal business hours. This can be a major inconvenience especially for shoppers who work long hours or shoppers who work odd hours. Online shopping eliminates this concern because shoppers can simply access online stores from their computer whenever they have free time available. Another convenience of online shopping is the ability to order products from around the world. Shoppers are no longer limited to products offered by local retailers because the vast majority of online retailers offer shipping to many different locations. This can make it easy for online shoppers to acquire hard to find items or items which are a regional specialty of a particular area.

\section{Data Analysis}

To identify general online shopping experience among participants, descriptive and comparative analyses of responses were completed. Participants' responses on general online shopping experience allowed for the categories based on years of online shopping experience. Once again, based on their responses, participants were placed into two groups for a comparative analysis. These and other descriptive variables were used to identify how often and how long both generations have been using the online shopping and what was the preferred payment method. The data between both the digital natives and the digital immigrants were compared in the analysis as well. The analysis of the responses to these questions included comparison of means and standard deviations. A descriptive statistics, as well as the data obtained from the $t$-Test has been carried out in this study. Overall the data analysis has been carried out to answers the 6 research questions formulated for this study which can be summarized in Table 1 . 
Table 1: Formulated Data Analysis Table

\begin{tabular}{ll}
\hline No & $\begin{array}{l}\text { Data } \\
\text { Rnalysis } \\
\text { and the Digital Immigrants? } \\
\text { RQ2: Is there a difference in the degree of satisfaction between the Digital Natives and the } \\
\text { Digital Immigrants? } \\
\text { RQ3: Is there a difference in perceive ease of use of Online Shopping between the Digital } \\
\text { Natives and the Digital Immigrants? } \\
\text { RQ4: Is there a difference in perceive usefulness of Online Shopping between the Digital } \\
\text { Natives and the Digital Immigrants? } \\
\text { RQ5: How does the digital natives and the digital immigrants perceive ease of use of online } \\
\text { shopping? } \\
\text { RQ6: How do the digital natives and the digital immigrants perceive usefulness of online } \\
\text { shopping? }\end{array}$ \\
\end{tabular}

\section{Findings}

A descriptive and t-test statistics were used to analyze the data by using the Statistical Package for the Social Sciences (SPSS) for Windows Version 20.0. The mean and standard deviation of variables namely usage pattern, degree of satisfaction, perceived usefulness and perceived ease of use are shown in Table 2.

Table 2: Mean and Standard Deviation of the Variables

\begin{tabular}{|c|c|c|c|c|c|}
\hline Variables & Groups & $\mathbf{N}$ & Mean & $\begin{array}{c}\text { Std. } \\
\text { Deviation }\end{array}$ & $\begin{array}{l}\text { Std. Error } \\
\text { Mean }\end{array}$ \\
\hline \multirow{2}{*}{ Usage Pattern } & Digital Immigrants & 100 & 4.5500 & .50000 & .05000 \\
\hline & Digital Natives & 100 & 4.0275 & .41270 & .04127 \\
\hline \multirow{2}{*}{$\begin{array}{l}\text { Degree of } \\
\text { Satisfaction }\end{array}$} & Digital Immigrants & 100 & 4.3720 & .42760 & .04276 \\
\hline & Digital Natives & 100 & 3.9430 & .37044 & .03704 \\
\hline \multirow{2}{*}{$\begin{array}{l}\text { Perceived } \\
\text { Usefulness }\end{array}$} & Digital Immigrants & 100 & 4.6400 & .48242 & .04824 \\
\hline & Digital Natives & 100 & 4.1336 & .38666 & .03867 \\
\hline \multirow{2}{*}{$\begin{array}{l}\text { Perceived Ease } \\
\text { of Use }\end{array}$} & Digital Immigrants & 100 & 4.6367 & .47163 & .04716 \\
\hline & Digital Natives & 100 & 4.2467 & .44285 & .04429 \\
\hline
\end{tabular}

Table 2 shows the comparisons of the four variables between the two generations. The main variables (Usage Pattern, Degree of Satisfaction, Perceived Usefulness and Perceived Ease of Use) were analyzed and compared in terms of the mean and standard deviation. The findings obtained revealed that the mean for usage pattern, degree of satisfaction, the perceived ease of use and perceived usefulness for digital immigrants are higher that the digital natives, we can conclude that the digital Immigrants are more accepting the online shopping compared to the digital natives. Table 2 shows the mean and standard deviation of the variables computed.

\section{Hypothesis Testing for the Variables}

Table 3 shows the results of the hypothesis using t-Test for $\mathrm{Ho}_{1}, \mathrm{Ho}_{2}, \mathrm{Ho}_{3}$, and $\mathrm{Ho}_{4}$.

Table 3: Hypothesis Testing for the Variables of the Study

\begin{tabular}{|c|c|c|c|c|c|}
\hline \multicolumn{6}{|c|}{ Hypothesis Testing for the Variables } \\
\hline Variables & & $\mathbf{t}$ & Sig. (2-tailed) & $\begin{array}{c}\text { Mean } \\
\text { Difference }\end{array}$ & $\begin{array}{l}\text { Std. Error } \\
\text { Difference }\end{array}$ \\
\hline \multirow{3}{*}{$\begin{array}{l}\text { Usage Pattern } \\
\qquad\left(\mathrm{Ho}_{1}\right)\end{array}$} & Digital & & & & \\
\hline & Immigrants & 8.059 & .000 & 0.52250 & 0.06483 \\
\hline & Digital Natives & 8.059 & .000 & 0.52250 & 0.06483 \\
\hline \multirow{3}{*}{$\begin{array}{c}\text { Degree of } \\
\text { Satisfaction } \\
\left(\mathrm{Ho}_{2}\right)\end{array}$} & Digital & & & & \\
\hline & Immigrants & 7.583 & .000 & 0.42900 & 0.05657 \\
\hline & Digital Natives & 7.583 & .000 & 0.42900 & 0.05657 \\
\hline \multirow{3}{*}{$\begin{array}{c}\text { Perceived } \\
\text { Usefulness } \\
\left(\mathrm{Ho}_{3}\right)\end{array}$} & Digital & & & & \\
\hline & Immigrants & 8.190 & .000 & 0.50636 & 0.06182 \\
\hline & Digital Natives & 8.190 & .000 & 0.50636 & 0.06182 \\
\hline \multirow{2}{*}{$\begin{array}{c}\text { Perceived Ease of } \\
\text { Use } \\
\left(\mathrm{Ho}_{4}\right)\end{array}$} & $\begin{array}{l}\text { Digital } \\
\text { Immigrants }\end{array}$ & 6.028 & .000 & 0.39000 & 0.06470 \\
\hline & Digital Natives & 6.028 & .000 & 0.39000 & 0.06470 \\
\hline
\end{tabular}


$\underline{\mathrm{Ho}}_{1}:$ There is no significant difference in the usage pattern of online shopping between the Digital Natives and the Digital Immigrants.

An independent-samples t-test was conducted to compare the usage pattern of online shopping between the digital natives and the digital immigrants. The Sig. (2-Tailed) value in table 3 is .000 . This value is less than .05 . Thus, we can conclude that there is a significant difference in the scores for digital immigrants $(\mathrm{M}=4.5500$, $\mathrm{SD}=.50000)$ and digital natives $(\mathrm{M}=4.0275, \mathrm{SD}=.41270)$ where, $\mathrm{t}(198)=8.059$, $\mathrm{p}$-value $=.000$. This shows that we reject the $\mathrm{Ho}_{1}$ hypothesis of this study whereby there is a significant difference between the digital immigrants and digital natives.

$\mathrm{Ho}_{2}:$ There is no significant in the degree of satisfaction of online shopping between the Digital Natives and the Digital Immigrants.

For the degree of satisfaction, an independent-samples t-test was also conducted to compare the digital natives and the digital immigrants. The Sig. (2-Tailed) value in table 3 is 0.00 . This p-value is less than 05 . Thus, we can conclude that there is a significant difference in the scores for digital immigrants $(\mathrm{M}=4.3720$, $\mathrm{SD}=.42760)$ and digital natives $(\mathrm{M}=3.9430, \mathrm{SD}=.37044)$ where, $\mathrm{t}(198)=7.583$, $\mathrm{p}$-value $=.000$. This shows that we reject the $\mathrm{Ho}_{2}$ hypothesis of this study whereby there is a significant difference between the digital immigrants and digital natives.

$\mathrm{Ho}_{3}:$ There is no significant in perceive ease of use of online shopping between the Digital Natives and the Digital Immigrants.

An independent-samples t-test was conducted to compare the perceived ease of use of online shopping between the digital natives and the digital immigrants. The Sig. (2-Tailed) value in table 3 is 0.00 . This, p-value is lesser than .05. Thus, it shows that there is a significant difference in the scores for digital immigrants $(\mathrm{M}=4.6367, \mathrm{SD}=.47163)$ and digital natives $(\mathrm{M}=4.2467, \mathrm{SD}=.44285)$ where, $\mathrm{t}(198)=6.028, \mathrm{p}$-value $=.000$. This shows that we reject the $\mathrm{Ho}_{3}$ hypothesis of this study whereby there is a significant difference between the digital immigrants and digital natives.

Ho $_{4}:$ There is no significant difference in perceive usefulness of online shopping between the Digital Natives and the Digital Immigrants.

Finally for hypothesis Ho4, the finding also shows that there is a significant difference between the digital immigrants and the digital natives whereby the hypothesis test shows that the $\mathrm{p}$-value for perceived usefulness is .000 . This, p-value is lesser than .05 . Thus, we can conclude that there is a significant difference in the scores for digital immigrants $(\mathrm{M}=4.6400, \mathrm{SD}=.48242)$ and digital natives $(\mathrm{M}=4.1336, \mathrm{SD}=.38666)$ where, $\mathrm{t}$ $(198)=8.190, \mathrm{p}$-value $=.000$. This shows that we reject the $\mathrm{Ho}_{4}$ hypothesis of this study whereby there is a significant difference between the digital immigrants and digital natives.

Mean and Standard Deviation of Variables of Perceived Usefulness and Perceived Ease of Use of Online Shopping among Digital Immigrant and Digital Natives

Table 4 shows mean and standard deviation of variables of perceived usefulness and perceived ease of use.

Table 4: Descriptive Statistic (Mean) for Perceived Usefulness and Perceived Ease of Use

\begin{tabular}{llrr}
\hline Groups & & Perceived Usefulnes & $\begin{array}{r}\text { Perceived } \\
\text { Ease of Use }\end{array}$ \\
\hline \multirow{2}{*}{ Digital Immigrants } & Mean & 4.6400 & 4.6367 \\
\cline { 2 - 4 } & $\mathrm{N}$ & 100 & 100 \\
\cline { 2 - 4 } Digital Natives & Std. Deviation & .48242 & .47163 \\
\hline \multirow{2}{*}{ Total } & Mean & 4.1336 & 4.2467 \\
\cline { 2 - 4 } & $\mathrm{N}$ & 100 & 100 \\
\cline { 2 - 4 } & Std. Deviation & .38666 & .44285 \\
\hline & Mean & 4.3868 & 4.4417 \\
\cline { 2 - 4 } & $\mathrm{N}$ & 200 & .50643 \\
\cline { 2 - 4 } & Std. Deviation & .50456 & .49643 \\
& & &
\end{tabular}

The analyzed data were in the mean $(\mu)$ score, sample size, and standard deviation (SD). There are altogether eleven items to evaluate about the usefulness of online shopping. With the five point likert scale, "Perceived Usefulness" for the digital immigrant obtained 4.6400 of mean score compared to the digital natives 
with mean 4.1336 only. The findings obtained revealed that the mean for perceived usefulness for digital immigrants are higher that the digital natives.

In terms of "Perceived Ease of Use", there are six items in the questionnaire. The mean score of perceived ease of use of online shopping obtained in this section is 4.6367 for digital immigrants and 4.2467 for digital natives which indicates strongly that the digital immigrants agreed that the online shopping is very easy to be use in completing their shopping. The findings obtained revealed that the mean for perceived ease of use of digital immigrants are higher that the digital natives. The results revealed that for both perceived usefulness and perceived ease of use, the digital immigrants are adapting and accepting the online shopping compared to the digital natives. These scores indicate that both groups accept online shopping and they agree that it is useful and convenient to them.

RQ5: How does the digital natives and the digital immigrants perceive ease of use of online shopping? Table 5 shows mean and standard deviation of variables of perceived usefulness for each items of online shopping among digital immigrant and digital natives.

Table 5: Mean and Standard Deviation of Variables Scores of "Perceived Usefulness"(PU) for each items.

\begin{tabular}{|c|c|c|c|c|}
\hline \multirow[t]{2}{*}{ Items } & \multicolumn{2}{|c|}{$\begin{array}{r}\text { Digital } \\
\text { Immigrants } \\
\end{array}$} & \multicolumn{2}{|c|}{ Digital Natives } \\
\hline & Mean & $\begin{array}{l}\text { Standard } \\
\text { Deviation }\end{array}$ & Mean & $\begin{array}{l}\text { Standard } \\
\text { Deviation }\end{array}$ \\
\hline PU1: Online shopping makes my shopping easier. & 4.6400 & 0.48242 & 4.1500 & 0.41133 \\
\hline PU2: Online shopping gives me greater choice of product. & 4.6400 & 0.48242 & 4.0500 & 0.51981 \\
\hline $\begin{array}{l}\text { PU3: Online shopping offers convenience and time-saving } \\
\text { benefits to shoppers. }\end{array}$ & 4.6400 & 0.48242 & 4.1200 & 0.45572 \\
\hline $\begin{array}{l}\text { PU4: Online shopping operates } 24 \text { hours a week, seven days a } \\
\text { week, and can be accessed anywhere in the connected } \\
\text { world. }\end{array}$ & 4.6400 & 0.48242 & 4.0700 & 0.49757 \\
\hline $\begin{array}{l}\text { PU5: Online shopping overcomes the time and risk over } \\
\text { traditional shopping. }\end{array}$ & 4.6400 & 0.48242 & 4.1100 & 0.5104 \\
\hline $\begin{array}{l}\text { PU6: Online shopping allows shoppers to shop from the comfort } \\
\text { and convenience of home. }\end{array}$ & 4.6400 & 0.48242 & 4.1100 & 0.49021 \\
\hline $\begin{array}{l}\text { PU7: Online shopping does not allow you to travel to physical } \\
\text { storefronts. }\end{array}$ & 4.6400 & 0.48242 & 4.1400 & 0.51286 \\
\hline $\begin{array}{l}\text { PU8: Online shopping allows comparison and research of } \\
\text { products and prices. }\end{array}$ & 4.6400 & 0.48242 & 4.1400 & 0.44992 \\
\hline PU9: By shopping online it allows me to save time. & 4.6400 & 0.48242 & 4.1900 & 0.44256 \\
\hline $\begin{array}{l}\text { PU10: Online shopping reduces the risk of using big amount of } \\
\text { cash money. }\end{array}$ & 4.6400 & 0.48242 & 4.1700 & 0.4507 \\
\hline PU11: Overall online shopping is convenient. & 4.6400 & 0.48242 & 4.2200 & 0.41633 \\
\hline
\end{tabular}

According to table 5, users generally rated "agree" for all the items where the mean score of all items were more than 4.00. The small SD values indicate that the deviation of ratings is rather small. Digital immigrants has obtained an average mean score of 4.6400 for its usefulness of online shopping compared to 4.1336 mean scored by the digital natives. Users especially strongly agreed that online shopping is useful for them. The highest score among all is 4.6400 out of 5.00 for all eleven items meanwhile, for the digital natives, the lowest mean score is 4.0500 and the highest mean score is 4.2200 . This is due to users agree strongly that online shopping is useful for them. Besides that, item number eleven, "Overall online shopping is convenient" marked as the highest score mean for digital immigrants compared to the digital natives. These scores indicate that both groups accept online shopping and they agree that it is useful for them and are much more convenient to them. This also shows that the online shopping is much more accepted by the digital immigrants.

RQ6: How does the digital natives and the digital immigrants perceive usefulness of online shopping?

Table 6 shows mean and standard deviation of variables of perceived ease of use for each items of online shopping among digital immigrant and digital natives. 
The Acceptance and Use of Online Shopping by the Digital Natives and Digital Immigrants

Table 6: Mean and Standard Deviation of Variables Scores of "Perceived Ease of Use"(PE) for each items.

\begin{tabular}{|c|c|c|c|c|}
\hline \multirow{3}{*}{ Items } & \multicolumn{4}{|c|}{ Groups } \\
\hline & \multicolumn{2}{|c|}{ Digital Immigrants } & \multicolumn{2}{|c|}{ Digital Natives } \\
\hline & Mean & $\begin{array}{l}\text { Standard } \\
\text { Deviation }\end{array}$ & Mean & $\begin{array}{l}\text { Standard } \\
\text { Deviation }\end{array}$ \\
\hline PE1 : I found that online shopping is easy. & 4.6700 & .47258 & 4.2500 & .43519 \\
\hline $\begin{array}{l}\text { PE2: It's easy to access consumer reviews of any product } \\
\text { you can think of }\end{array}$ & 4.6700 & .47258 & 4.1800 & .57525 \\
\hline PE3 : It is easy for me to serve the online shopping sites. & 4.6200 & .48783 & 4.2400 & .49482 \\
\hline PE4 : It is easy to move from one online shop to another. & 4.6200 & .48783 & 4.2121 & .55829 \\
\hline PE5: I do not need a user manual to shop online. & 4.6200 & .48783 & 4.2800 & .45126 \\
\hline PE6 : Overall, I found shopping online is user friendly. & 4.6200 & .48783 & 4.3100 & .48607 \\
\hline
\end{tabular}

Digital immigrants have obtained an average mean score of 4.6367 for its ease of use meanwhile the digital natives has obtained only 4.2467 mean score. Again, all the items have scored more than 4.00 out of the five point scale for the survey instrument which means the users are generally agree or strongly agree with the ease of use of online shopping. The item number three, item number four, item number five and item number six scored the lowest mark, which is 4.6200 meanwhile the item number one and item number two scored the highest, which is 4.6700. However, the participants rated a mean score of 4.6200 for the item "Overall, I found shopping online is user friendly." As for digital natives, the low mean scores obtained for item number two is 4.1800 . According to table 6, only a mean score of 4.3100 for the item "Overall, I found shopping online is user friendly". This result indicates strongly that the digital immigrants agreed that the online shopping is very easy to be use in completing their shopping. The results revealed that the digital immigrants are more user friendly of the online shopping than the digital natives.

\section{Discussions}

The computed marks collected from SPSS were compared with 2 generations which is the digital natives and the digital immigrants. This comparison was done only among 100 participants each and the four main components (Usage Pattern, Degree of Satisfaction, Perceived Usefulness and Perceived Ease of Use) that were analyzed were taken the average mean. Technology Acceptance Model (TAM) by Davis et al. (1989) theory has been applied in this study. A test model of theory was analyzed from 200 staffs and students. Since there is no previous research investigating the factors of acceptance level of online shopping among both generations, this study gave new insight into the role of four main factors it may impact a broader acceptance and development of online shopping.

One needs to understand the differences in digital immigrants and digital natives because of how these two groups interact as the digital immigrants are the parents, teachers, and managers of digital natives. As the Internet has grown dramatically every year since the beginning of the 1990s, and the diffusion of online buying transactions is readily accepted by consumers in some countries, in others consumers seem to be less accepting.

In this study, the finding revealed that for Ho1; There is no significant difference in the usage pattern of online shopping between the digital natives and the digital immigrants. The finding also shows that there is significant difference between the digital immigrants and the digital natives whereby the hypothesis test shows the p-value for usage pattern is .000 . This finding show that we reject the null hypothesis of this study whereby there is a significant difference between the digital immigrants and digital natives. Prensky, M. (2001), stated that the digital immigrants lived in two cultures: the pre-digital and the digital. Digital natives have known only the digital culture. A great many of the digital immigrants' deeply-felt attitudes and preferences were formed in, and reflect, the pre-digital culture and age. And thus the findings revealed that the usage pattern of online shopping for digital immigrants are higher that the digital natives. These finding seems to be aligned with Ofer Zur (2011) and Murdoch (2005), which the digital immigrant can be the eager adopters, enthusiastic participants embrace and use all forms of digital technology. This group prefers texting and tweeting over sending out email blasts. They are aware of the latest technology, trends, and tools. Their online and offline lives are blending together. Moreover, Ofer Zur has also classified by some interesting research on the digital immigrants whereby, this group is aware that digital technology is a part of their daily life. They choose to interact with only the most interesting things to them personally.

On the other hand for Ho2; There is no significant in the degree of satisfaction between the digital natives and the digital immigrants, the finding shows that there is significant difference between the digital immigrants and the digital natives whereby the hypothesis test shows the p-value for degree of satisfaction is .000. This finding show that we reject the Ho2 hypothesis whereby there is a significant difference between the Digital Immigrants and Digital Natives. Most customers form expectation about the product vendor, service and quality of the website that they patronize before engaging in online shopping activities. These expectations influence their decision making and intention to shop at a certain Internet store and consequently, their decision 
making process and purchasing behavior. If expectations are met, customers achieve a high degree of satisfaction which influences their online shopping attitudes, intentions and decisions positively. These finding was supported by the factors that influence online shopper's satisfaction that included convenience (Heiner et al., 2004), web site design, security/ privacy, payment, and delivery (Liu et al., 2008). Moreover, studies like Ahn et al. (2004); Szymanki and Hise (2000) and Athanassopoulos et al (2001) who has found that the product variety as an important factor influencing satisfaction. When it comes to payment, a lot of participants are concerned about the identity theft when hear about online shopping. Identity theft cases take place in reality in brick and mortar store itself and not online. Websites are secure these days with powerful encryption procedures that keep their identity safe and secure.

One can take a peaceful breathe when dealing with the vast majority of online shopping website. Besides that they also consider websites that offer free shipping and this is definitely the way to go. As the price of gas is increasing, shipping and handling is much more be cheaper. Time and cost saving are the main advantages of online shopping. According to Devaraj et al. (2002) time efficiency and store efficiency are reflected in time cost and price savings respectively determinants the satisfaction. Besides that, Lee and Joshi (2007); Ahn et al. (2004); Ho (2004); Grewal et al (2004) and Shih (2004) studies found that delivery performance has significant influence on customer satisfaction. Meanwhile for Ho3; There is no significant in perceive ease of use of online shopping between the digital natives and the digital immigrants.

For the perceived usefulness, the null hypothesis test shows the p-value for perceived ease of use is .000 whereby the finding shows there is a significant difference between the digital immigrants and digital natives and we also reject the Ho3. These finding seems to be aligned with Zur, O. \& Zur, A. (2011), who stated that enthusiastic adopters are the digital immigrants who have the potential to keep up with natives, due to their ease, capacity, and interest in using technology. They may be high-tech executives, programmers, businesspeople and others who embrace technology and immerse themselves in the Internet culture. This group sees the value of technology and does their best to make use of it. Some members of this group are Bill Gates who falls in the digital immigrants group. Members of this group text, use Skype, have and use a Facebook account (recognizing that this is the best way to interact with their kids in a favored medium and connect with old friends), check email regularly, and are excited about new gadgets and tech developments. It can be concluded, in a simplified manner, that ease of use is how easy the Internet is to use as a tool for shopping, and usefulness describes how effective online shopping is in helping consumers in completing their task.

Finally for Ho4; There is no significant difference in perceive usefulness of online shopping between the digital natives and the digital immigrants. Finally for the null hypothesis ho4, it also rejects the null hypothesis as the p-value results shows there is a significant difference of .000 between the digital immigrants and digital natives. this is also consist of the finding by Dellaert et al. (2004) who classifies the new technology as shopping on the Internet and the individual's performance as the outcome of the online shopping experience. One of the most obvious benefits of online shopping which cannot be overlooked is convenience. Online shopping is that it allows them to browse through many items and categories without leaving their house, to compare the prices of as many shops as they want, and also to order as many items as they can afford without having to worry about how they will transport them, because the online shopping websites also deliver the things to their home. According to the results above, the digital immigrants finds online shopping is useful and easy. This is because they are all senior citizens, educated professionals and they are IT literate. Besides that this group also finds online shopping more convenience and comfortable.

Furthermore, the Internet is accessible 24 hours a day, 365 days a year, so the digital immigrants don't have to hurry or worry about finding a parking spot. Definitely the digital immigrant would like to avoid the crowds when they do the shopping. Especially during Festivals and Special events the crowds can really give a head ache. Crowds forces to do a hurry shopping most of the time. Crowds also create a problem when it comes to finding a parking place nearby where you want to shop and going back to their vehicle later loaded with shopping bags. Besides that, many times they end up buying things which they do not require because of the shop keepers up selling skills. This research finding revealed that for both perceived usefulness and perceived ease of use, both the digital immigrants are adapting and accepting the online shopping compared to the digital natives.

The finding shows that there is significant difference between the digital immigrants and the digital natives whereby the scores for usage pattern, degree of satisfaction, perceived usefulness and perceived ease of use. This finding show that we reject all the four hypothesis of this study whereby there is significant differences between the digital immigrants and digital natives.

\section{Limitation Of The Study}

This study is restricted to the choice of samples for this study is 100 digital natives and the 100 digital immigrants who can be considered as the convenience sample in this study because they are readily available to the researcher. Among them is the sample size, the inclusion of only one Public University in Peninsular 
Malaysia. There are two generations in this research study that is being examined. A bigger scale study needs to be conducted for more reliable results, and with the inclusion of more variables such as family background, reading exposure and availability of reading materials, and variables that are related specifically with reading in the digital environment.

\section{Recommendations}

Future research is necessary to reconsider and re-examine the relationship between demographic variables such as gender and level of educations, as well as attitude and intention in the context of online shopping acceptance to generalize the result to whole Malaysians. The findings of this study imply that the overall acceptance level of Malaysians toward online shopping is encouraging. This study has provided a foundation to both practitioners (Immigrants and Natives) and academicians and students for understanding of the acceptance level of online shopping, and the characteristics the online shopping users (especially Usefulness and Ease-of-Use). Future studies can also be extended to include respondents from different area and socioeconomic related variables.

\section{Conclusion}

The objective of this research has been achieved as the results revealed that for both perceived usefulness and perceived ease of use, both the digital immigrants are adapting and accepting the online shopping compared to the digital natives. The finding shows that there is a significant difference between the digital immigrants and the digital natives as the p-value for Usage Pattern, Degree of Satisfaction, Perceived Usefulness and Perceived Ease of Use is .000. This finding show that it fails to accept all the four null hypothesis of this study whereby there is significant differences between the digital immigrants and digital natives.

As a summary, study done on the acceptance of online shopping among the digital immigrants and the digital natives has shown that the digital immigrants is well accepted by its users in terms of the usage pattern, degree of satisfaction, usefulness, and ease of use. the digital immigrants generally found that online shopping is truly useful for them to complete their shopping tasks as online shopping has enhanced their works and reduced their time. Besides, online shopping is also very user-friendly. Most of the users had no problems in handling the shopping websites without a user manual. They strongly agreed it is useful and it's easy to shop online all for them. To conclude, the acceptance of online shopping among the digital immigrants is well accepted not only due to its usefulness; ease of use and convenience compare to the digital natives.

\section{References}

[1] Ajzen, I., Fishbein, M., \& Heilbroner, R. L. (1980). Understanding attitudes and predicting social behavior (3ed.).Englewood Cliffs, NJ: Prentice-Hall.

[2] Davis, F. D. (1986). A technology acceptance model for empirically testing new end-user information systems: theory and results (Unpublished Doctoral Dissertation). Massachusetts Institute of Technology.

[3] Davis, F. D. (1989). Perceived usefulness, perceived ease of use, and user acceptance of information technology. Management Information Systems Research Center, University of Minnesota, 13(3), 319-340.

[4] Davis, F. D. (1993). User acceptance of information technology: system characteristics, user perceptions, and behavioral impacts. Int. J. Man-Machine Studies, 38, 475-487.

[5] Liu, I.-F., Chen, M. C., Sun, Y. S., Wible, D., \& Kuo, C.-H. (2010). Extending the TAM model to explore the factors that affect Intention to Use an Online Learning Community. Computers \& Education, 54, 600-610.

[6] Calhoun, K. J., Teng, J. T. C., \& Cheon, M. J. (2002). Impact of national culture on information technology usage behaviour: An exploratory study of decision making in Korea and the USA. Behaviour \& Information Technology, 21(4), $293-302$.

[7] Chandler, C., Levinstein, J., \& Wang, F. (2007). China's Web king. Fortune, 156, 52-57. Chau, P. Y. K., Cole, M., Massey, A. P., Montoya-Weiss, M., \& O'Keefe, R. M. (2002).

[8] Cultural differences in the online behavior of consumers. Communications of the ACM, 45(10), 138-143.

[9] Chen, Y. (2006). Factors that affect online consumer trust in Taiwan (Doctoral dissertation, Lynn University). Available from ProQuest Dissertations and Theses database. (UMI No. 3223492)

[10] Dieter, E., \& He, J. (2000). The future of E-Commerce in China. Asia Pacific Issues, 46.

[11] Fong, J., \& Burton, S. (2006). Electronic word-of-mouth: A comparison of stated and revealed behavior on electronic discussion boards. Journal of Interactive Advertising, 6(2), 53-62.

[12] Heiner, E., Gopalkrishnan, R.I., Josef, H., \& Dieter, A. (2004), E-satisfaction: a re- examination, Journal of Retailing, 80(3), 239247.

[13] Hofstede, G. \& Hofstede, G. J., (2005). Cultures and organizations: software of the mind. New York: The McGraw-Hill Companies.

[14] Kotler, P. (1997), Marketing Management: Analysis, Planning, Implementation, and Control. New Jersey:

[15] Liu, X., He, M., Gao, F., \& Xie, P., (2008). An empirical study of online shopping customer satisfaction in China: a holistic perspective. International Journal of Retail \& Distribution Management, 36(11), 919-940.

[16] Lu, H.T. (2005). The behavior differences of Chinese consumers. Beijing: Chinese Social Science Press.

[17] Ranganathan, C., \& Ganapathy, S. (2002), Key dimensions of business-to-customer website. Information \& Management, 39(6), 457- 465 .

[18] Rein, S. (2007). Chinese Cozy Up to E-Commerce. Business Week Online, 2/9/2007(2/9/2007), 11-11

[19] Roger, E. M., Diffusion of innovations, 3rd ed., New York: The Free Press. 
[20] Teo, T. S. H., \& Liu, J. (2007). Consumer trust in e-commerce in the United States, Singapore and China. The International Journal of Management Science, 2007.

[21] Mark Prensky: Don't Bother Me Mom--I'm Learning! http://www.amazon.com/Dont-Bother-Me-Mom-ImLearning/dp/1557788588/ref=pd_sim_b_5

[22] Zur, O. \& Zur, A. (2011): On Digital Immigrants and Digital Natives: How the Digital Divide Affects Families, Educational Institutions, and the Workplace.

[23] Harding, Tucker. (2010). Digital Natives and Digital Immigrants. Retrieved on February 3 , 2011 from http://ccnmtl.columbia.edu/enhanced/primers/digital_natives.html

[24] Prensky, M. (2001). Digital natives, digital immigrants. On the Horizon 9 (5). Retrieved Jan., 29, 2011, from http://www.marcprensky.com/writing/Prensky\%20-20Digital\%20Natives,\%20Digital\%20Immigrants\%20-\%20Part1.pdf

[25] Rosen, L. (2010). Rewired: Understanding the iGeneration and the Way They Learn. New York: Palgrave Macmilla. 